(56.7 per cent.) where spinal venules were absent 71 per cent. were noted as of "good" nutrition. Only 9 cases $(9.6$ per cent.) showed dilated chest veins, and in 3 ( 3 per cent.) paravertebral dullness pointed to enlarged glands.

The higher incidence of dilated chest veins and paravertebral dullness in the first group suggests a connexion between the spinal telangiectases and enlargement of intrathoracic glands, and hence tuberculosis. In an investigation recently made by myself into the incidence and characteristics of manifest tuberculosis among children from tuberculous households it was found that $41^{\prime} 7$ per cent. (among 24 children) showed these spinal venules, while they were present in only 23 per cent. of children (22 in number) drawn from healthy house. holds in the same neighbourhood. Among the whole the incidence of venules where manifest signs of disease (mostly glandular) were present was just twice that among those with apparently normal chests. Here, again, there is evidence to suggest that the dilated spinal venules are, like dilated veins over the chest, in many cases at least, of pressure origin, and owe their presence, as was suggested by W. Overend as long ago as 1901, to pressure on right or left superior intercostal vein, or on the vena azygos major into which the former opens. Their special association with enlargement of tracheo-bronchial glands might thus be expected; but, curiously enough, where signs of this occurred among the subjects of my investigation mentioned above, the spinal venules were more often absent than present (in 8 among 10). In some cases, and notably where, as in four cases referred to, similar telangiectases are also present over other parts of the body, they are very probably of nævoid nature and allied to the venules so often present in the red parts of the cheek.

As to the value of the spinal venules in diagnosis, this may be readily gauged from their presence in over 40 per cent. of healthy young people. Even if it must be admitted, as it readily would be by myself, that the 40 per cent. were probably tuberculous, this knowledge would still avail us but little. since in civilised communities our diagnosis is not required to discriminate as a rule between the tubercle-free and the tuberculous, but between the tuberculous "healthy" and the tuberculous "diseased."

I am, Sir, yours faithfully,

Queen Anne-street, W., March 18th, 1916. CLrve RIviere.

\section{THYMO-BENZENE IN BILHARZIOSIS.}

To the Editor of THE LANCET.

SIR,-Mr. J. F. Briscoe's letter in THE LANCET of Jan. 15th on bilharziosis induces me to refer to the invariably good results of the treatment of this infection with thymo-benzene in doses of $2 \mathrm{gr}$. of the former and $3 \mathrm{ss}$ of the benzene. The thymol dissolves freely in the benzene. Given in such doses on the third day the ova are found in shoals on the slides, the majority being black. This is brought about, I suppose, by the benzene invalidating the outer envelope of the ovum and allowing blood pigments to colour the contents, miracidium, \&c. In very nearly the same time and with continuation of the drugs all the subjective and objective sym. ptoms abate. Sleep is restored, pain diminishes, and the patient rests quietly in bed at night. Giddiness is no longer complained of. The urine soon loses all appearance of blood, becomes normal in colour, with disappearance of sediment and albumin. The anæmia soon disappears, and with returning appetite strength and weight improve.
Mild cases in robust subjects lose all trace of the infection in a few weeks, no ova being found in the urine after repeated examination. In graver cases in depraved constitutions the result is not so good, but even here the patient loses all his symptoms with the exception of a few ova in the urine.

I have supposed that in the one case the worms have been in some way invalidated, toxins have evidently been rendered harmless, while secondary infections have been quite abolished. I know of no other remedy that can effect such results in this infection. It is not poisonous, and the doses above referred to have in no case given the slightest discomfort.-I am, Sir, yours faithfully, St. Mark's, Cape Province, South Africa. Wir. ROBERTSON.

\section{THE TREATMENT OF HAMORRHOIDS BY INJECTION.}

To the Editor of THE LANCET.

SIR,-A simple story is recalled to my mind by $\mathrm{Mr}$. A. S. Morley's able summary of the pros and cons of the injection treatment of hæmorrhoids in your last issue.

There was once a king in Erewhon who, like many a rich layman since his day, thought to ensure his bodily health by having a variety of medical advice. So he attached to his court two alchemists (or, as some say, phy. sicians). Their names were Bubble and Squeak, and there was great rivalry between them.

Now, in the course of his researches Bubble discovered a herb with which he claimed he could cure the fundamental ailments of the human body. (Bubble was the first proctologist in history.) Squeak said that Bubble was a quack and that the herb was not only useless but also dangerous.

One day the king's wife developed a small pile. She consulted Bubble and he cured her. So the king, who was a just king, cut off Squeak's head because he was a liar. And later on the king himself developed a pile, but a large and troublesome one, which prolapsed and was irreducible if he became excited, as kings do. He too tried Bubble's remedy, but it failed. So the king, who was a just king, cut off Bubble's head. because he was a liar.

The herb, though for all we know it had its uses, fell into disrepute. This was the result of the exaggeration of the enthusiast on the one hand and the bigotry of the sceptic on the other.

I have attempted elsewhere ${ }^{1}$ to state the situa. tion precisely. The truth is that the injection treat. ment is not quackery, as some have alleged, nor is it infallible, as others would have one believe; but that in properly selected cases it will often effect a cure and thus avoid an operation, to the great gratification of the patient.

$$
\text { I am, Sir, yours faithfully, }
$$

Queen Anne-street, W.. March 20th, $1916 . \quad$ IVOR BACK.

\section{SHELL SHOCK.}

\section{To the Editor of THE LANCET.}

SIR,-Lieutenant-Colonel Charles S. Myers in his communication on shell shock in THE LANCET of March 18th quotes two cases which illustrate a principle the application of which has receired but little attention in connexion with the war. Cases 10 and 11 are the only two in which he records the visual acuity. In both cases the unilateral symptoms mentioned are on the side of the eye with the worse visual acuity; in the one case, right frontal headache, tremors of the right arm and weakened grip of the right hand, right hemianalgesia, hemianæsthesia, hemianosmia and hemiageusia, loss of stereognostic and vibra. tion sense on the right side, right nerre-deafness and limitation of the right visual field; in 